Research Article

\title{
Numerical Simulation on Cutting and Fracturing of Rock Plate with One Side Fixed and Three Sides Free
}

\author{
Zhenguo Lu $\left(\mathbb{D},{ }^{1,2}\right.$ Qingliang Zeng $\mathbb{D}^{2,3}$ Zhaosheng Meng ${ }^{2}{ }^{4}{ }^{4}$ Zhiwen Wang, ${ }^{3}$ \\ and Guanshun Gao (D) $^{3}$ \\ ${ }^{1}$ College of Transportation, Shandong University of Science and Technology, Qingdao 266590, China \\ ${ }^{2}$ Shandong Province Key Laboratory of Mine Mechanical Engineering, Shandong University of Science and Technology, \\ Qingdao 266590, China \\ ${ }^{3}$ College of Mechanical and Electronic Engineering, Shandong University of Science and Technology, Qingdao 266590, China \\ ${ }^{4}$ State Key Laboratory of Mining Disaster Prevention and Control Cofounded by Shandong Province and the Ministry of Science \\ and Technology, Shandong University of Science and Technology, Qingdao 266590, China
}

Correspondence should be addressed to Zhaosheng Meng; skdmzs@163.com

Received 11 April 2020; Revised 24 May 2020; Accepted 28 May 2020; Published 30 June 2020

Academic Editor: Hiroshi Yoshihara

Copyright (c) 2020 Zhenguo Lu et al. This is an open access article distributed under the Creative Commons Attribution License, which permits unrestricted use, distribution, and reproduction in any medium, provided the original work is properly cited.

Conical pick is a rock cutting tool that is commonly used in roadway driving. Pick wear frequently happens in the course of breaking hard rock. The current paper shows a new method to solve the problem of pick wear. The rock is preslit with the saw blade and then broken by the conical pick. In order to study the cutting force and features of rock fragment, the numerical model is built between rock plate and conical pick. And element erosion is added in the code to obtain the fracture result. The rock plate cutting testbed is made to testify the correctness of numerical simulation. The width, height, and thickness of the rock plate, as well as cutting angle and cutting position, which influence cutting force and rock fracture are studied. According to the results, there exist exponential relationships between cutting force and width and thickness of rock plate. In addition, a linear relationship is found between the cutting force and the height of rock plate. Furthermore, both the cutting angle and cutting depth have an influence on cutting force. In particular, the factors of thickness and height or rock plate have the most obvious influence on cutting force. It is proven that what is beneficial to rock fracture is higher height and lower thickness of rock plate.

\section{Introduction}

Mechanical excavation is the most widely used rock excavation approach in the mining and civil industries [1]. As a common cutting tool, the selection of conical pick is influenced by many factors, such as the strength of rock, rock cutting depth, and the cost of the cutting tool itself. Therefore, the research of the rock fracture mechanism is particularly important for conical pick design.

In order to improve the efficiency of rock breaking, scholars have done comprehensive research on the rock cutting mechanism by various methods. The most classical theoretical study shows the cutting depth of conical pick and compressive and tensile strength of rock as the main parameter influencing cutting force [2]. However, when the tip angle of the conical pick is equal to zero, the cutting force still exists. Friction angle is introduced to overcome the shortcoming of the theoretical model; meanwhile, the experiments indicate that the results obtained from the new theories are closer to reality [3-6]. Liu and Jin [7] prove that cutting force is also in relevance to the number and layout of the conical pick. The influential factors on cutting force are systematically researched in experimental approach. The factors influencing cutting force are more than uniaxial compressive strength and cutting depth; meanwhile, elastic modulus and tensile strength are also the significantly influencing factors [8]. To reduce the experimental cost, Kang et al. [9] build a small capacity cutting testbed, and the feasibility of the scheme is proved by experiment and simulation. Dewangan and Chattopadhyaya [10] give a 
cutting angle optimization suggestion based on cutting efficiency and temperature of the conical pick. With the rock cutting machine, the cutting performance at the relieved cutting method is predicted [11]. Huang et al. [12] take deep mining condition into account and research the relationship between confining stress and cutting force. Wang et al. [13] propose a specific energy model with regression methods, which is verified by experiment. Su [14] employs PFC 3D code to build the interaction model between cutter and rock and gives the relationship between rake angle and cutting depth. Meanwhile, he demonstrates that the Nishimatsu theory is only suitable for hard rock. Wang and Su [15] point out that the maximum volume of rock fragment is proportional to cutting depth and that the specific energy decreases exponentially with the increase of cutting depth. Yasar $[16,17]$ points out that there are inherent defects in the traditional theoretical model. Test results of different rocks show that semitheoretical model of rock cutting can better reflect the actual situation. Meanwhile, Yasar demonstrates that it is feasible to use small block sample to predict cutting force. Lu et al. [18] conclude that cutting speed does not influence cutting force or fracture characteristics, after researching the fracture features of a free rock plate with three sides fixed and one side free. Pick wear is an important factor that influences cutting efficiency and production cost. To reveal the mechanism of pick wear and the influencing factors, pick wear at different working conditions is analyzed $[19,20]$. The rock cutting method assisted by a high-pressure water jet is firstly proposed by Michael [21]. In recent years, how to improve cutting ability and avoid pick wear in the hard rock cutting process has become a research hotspot. Stoxreiter et al. [22] combine high-pressure water jet and mechanical excavation technology, and their research shows that high-pressure jetting is an effective approach to break the hard rock. Poláček and Janurová [23] research with an experiment the relationship between the pressure of water jet and rock breaking state. Wang et al. [24] propose a stress released rock cutting method to improve rock cutability via experimental and simulation method. By releasing high stress concentration to lower or none stress condition, rock produces a damage area, thereby the rock cutting ability is improved. However, due to the limitation of mine and rock production conditions, the methods mentioned before are difficult to apply and popularize. In order to reveal the wear mechanism of conical pick, Liu et al. [25] propose finite element method to research cutting form and the characteristics of cutting force influencing pick wear. It is considered that the interference between the back of the pick and the rock is the main factor that causes wear of the pick. Their research shows that rotation of the pick is also the main reason influencing the wear of pick [26]. Li et al. [27] carry out the linear cutting test of rock by using conical pick, pointing out that the main failure mode of pick is plastic failure. Kim et al. [28] research the skew angle influencing the temperature and wear of the conical pick by bench-scale device. The results show that large tip surface area has a significant influence on temperature.

Although scholars have conducted extensive researches on rock cutting mechanism and wear mechanism of conical pick, pick wear is still ubiquitous in hard rock cutting. A diamond saw blade and conical pick combined rock cutting method is proposed in this paper. And the interaction model between the conical pick and rock plate is established to study the fracture morphology and cutting force of rock plate formed by sawing. The factors influencing rock fracture morphology and cutting force are studied. In order to verify the correctness and feasibility of the numerical method, experiments are conducted to test the numerical results.

\section{Method}

2.1. Proposal of the New Rock Cutting Method. Conical pick wear is a serious problem in roadway excavation, and it is an unfavorable factor to increase the cost of production. As is well known, diamond is a very hard substance; therefore, diamond saw blade is a common cutting tool in the stone processing industry, which can slit the rock easily. Thus, the rock plate with multiple free surfaces can be formed. As a result, the cutability of rock can be effectively improved. Then, the cutting head of roadheader will be used to cut the rock plate, as is shown in Figure 1. The schematic drawing of the new roadheader is shown in Figure 2. Compared with conventional roadheader, the saw blade assembly and its drive unit are added.

The rock plate with three sides fixed and one side free is formed by cutting with diamond saw blade, as is shown in Figure 3(a). But in rock cutting, it is most possible that the rock plate with one side fixed and three sides free is formed. Therefore, this paper takes rock plate with one side fixed and three sides free as the focus of research.

2.2. Numerical Model. The software chosen is very important for getting reliable and scientific results. LS-DYNA is a typical nonlinear dynamic analysis software, with great advantages in collision analysis. In the paper, LS-DYNA is employed to establish the finite element model which consists of two parts, that is, rock and conical pick. Meanwhile, the rock also contains two parts, base rock and rock plate. It should be pointed out that the rock plate and base bock are an integral structure instead of two independent parts, as shown in Figure 4. The hexahedral grid element is employed for rock division. All the nodes at the bottom of base rock are defined as a node group, and all degrees of freedom of the node group are constrained. In order to eliminate stress wave influencing rock fracture and stress distribution, nonreflection boundary condition is added to all of the elements. The conical pick is used to cut the fixed rock with constant velocity. $l_{x}, l_{y}$, and $l_{z}$ are the width, thickness, and height of rock plate, respectively. In order to research cutting position influencing rock cutting performance, $l_{x p}$ was employed to express the distance between the conical pick and left boundary of the rock plate. In the xoy plane, the angle between velocity of conical pick and the $y$-axis is defined as cutting angle, expressed by $\beta$ in Figure 4. JOHNSON_HOLMQUIST_CONCRETE (JHC) [29] and EROSION was assigned to the rock for obtaining the superior rock fracture result. The contact model 


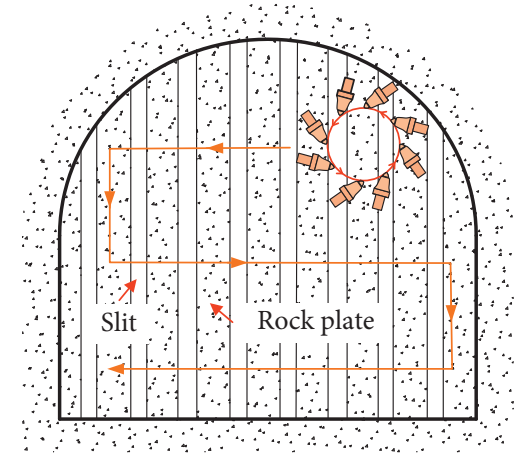

Figure 1: Schematic drawing of the application of the new rock cutting method.

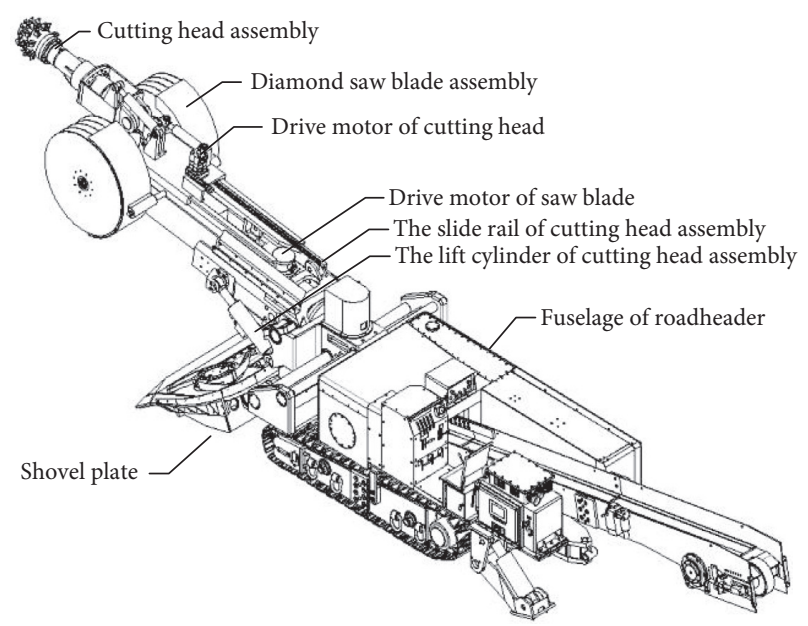

FIGURE 2: Schematic drawing of the roadheader combing diamond saw blade and conical pick.

ERODING_SURFACE_TO_SURFACE is assigned between conical pick and rock. Because the finite element model in this paper contains a small number of elements, the conical pick part is a rigid body. With workstations, each group of data takes about three hours to calculate, which is not long. Therefore, mass scaling is not used for numerical simulation in this paper. The hourglass energy has a significant influence on the simulation calculation results. In order to avoid the hourglass, in this paper, full integration is used in model calculation, and there is no hourglass energy generated in the simulation calculation process, so the influence of hourglass does not need to be considered in this paper. Taking granite as an example, its main parameters are shown in Table 1.

2.3. Experimental Verification. Mechanical properties are basic for experimental and numerical simulation, especially the Brazilian tensile strength (BTS), uniaxial compressive strength (UCS), elastic modulus $(E)$, and density $(D)$ of rock. An electrohydraulic servo testing machine is used to obtain the uniaxial compressive strength and elastic modulus of rock specimens, as is shown in Figure 5(a), and the stressstrain curve, as is shown in Figure 5(b). The maximum value of the curve is the UCS. The elastic modulus is calculated at the $50 \%$ maximum compressive strength; similarly, the average value of three tests is taken. The tensile strength can be obtained by the Brazilian split test, and the density of rock can be obtained from balance. In order to ensure the accuracy of the test results, three groups of tests are conducted for each data. The mechanical properties of marble, Granite, sandstone-1, and sandstone-2 are shown in Table 2.

Only few studies on the fracture characteristics of rock plate cutting are found. In order to verify the correctness of the numerical simulation in the paper, a rock plate cutting testbed was built, as is shown in Figure 6 .

Figure 7 shows the cutting results of a rock plate of granite with width of $500 \mathrm{~mm}$, height of $200 \mathrm{~mm}$, and thickness of $20 \mathrm{~mm}$. On the same numerical simulation and experimental cutting conditions, the fracture morphology of rock plate is basically the same. The fracture occurs at the junction of rock plate and base rock and in the middle of rock plate. Therefore, the numerical simulation method employed in the paper is accurate and feasible.

\section{Results and Discussion}

3.1. Influence of Width on Rock Plate Fracture. The cutting results of granite with different widths are shown in Figure 8. At width of $60 \mathrm{~mm}$ and $80 \mathrm{~mm}$, rock plate integral fractures at the junction between base rock and rock plate are shown in Figures 8(a) and 8(b). Under the action of cutting force, element fails at the contact area between rock plate and conical pick. However, when width of rock plate increases to $200 \mathrm{~mm}$ and $400 \mathrm{~mm}$, the rock plate is broken into two parts. The main cracks are located in the middle of rock plate as well as at the junction between rock plate and base rock. The numerical results are the same as the experimental results, which demonstrate that the numerical simulation is feasible. As the conical pick moves, the maximum bending moment is produced at the junction of base rock and rock plate, which leads to rock plate broken. When width of rock plate increases, larger deflection and internal force are produced in the width direction of rock plate, so that the rock plate is broken in the middle.

The peak cutting force (PCF) variation with width and the fitting curve between them are shown in Figures 9 and 10. It can be seen that PCF increases when the width of rock plate increases. The PCF at $500 \mathrm{~mm}$ increases with small value, compared with that of $400 \mathrm{~mm}$. Thus, with the increase of width, the increasing amplitude of PFC decreases. In the industrial production process, even if the width of rock plate is very large, the PCF will not be very large. The fitting results between width and PCF with a thickness of $20 \mathrm{~mm}$ are shown in Table 3. It can be seen from the fitting equation that the exponential-positive relationship exists between PCF and width of rock plate. All of the correlation coefficients are greater than 0.9 , so the fitting results are reliable. The statistical $P$ values are less than 0.01 , which show that the results are significant.

3.2. Influence of Height on Rock Plate Fracture. The cutting results of rock plate of granite at the heights of $20 \mathrm{~mm}$ and 


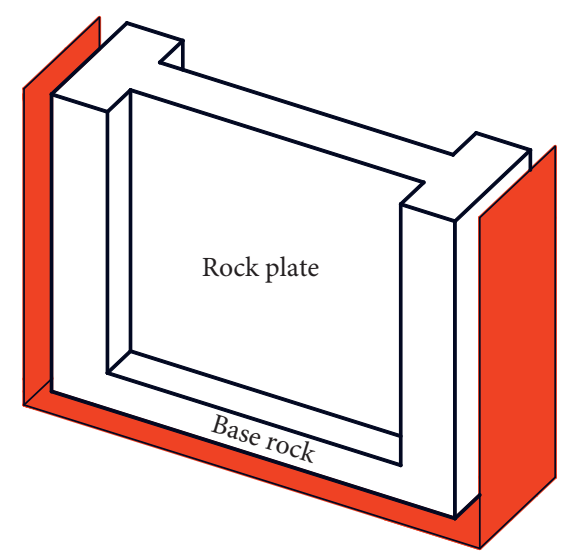

(a)

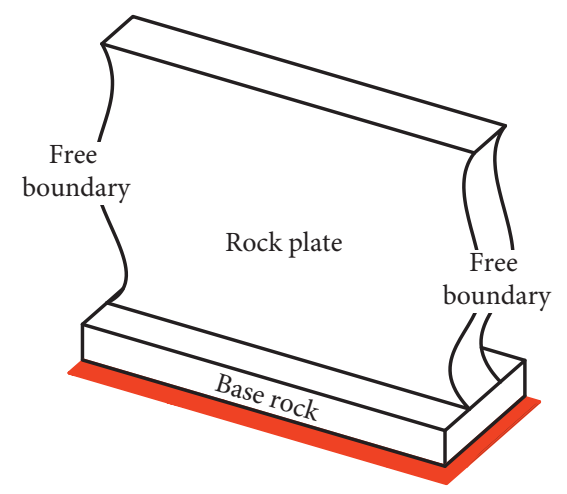

(b)

Figure 3: Rock plate with different constraint boundaries: (a) three sides fixed and one side free and (b) one side fixed and three side free.

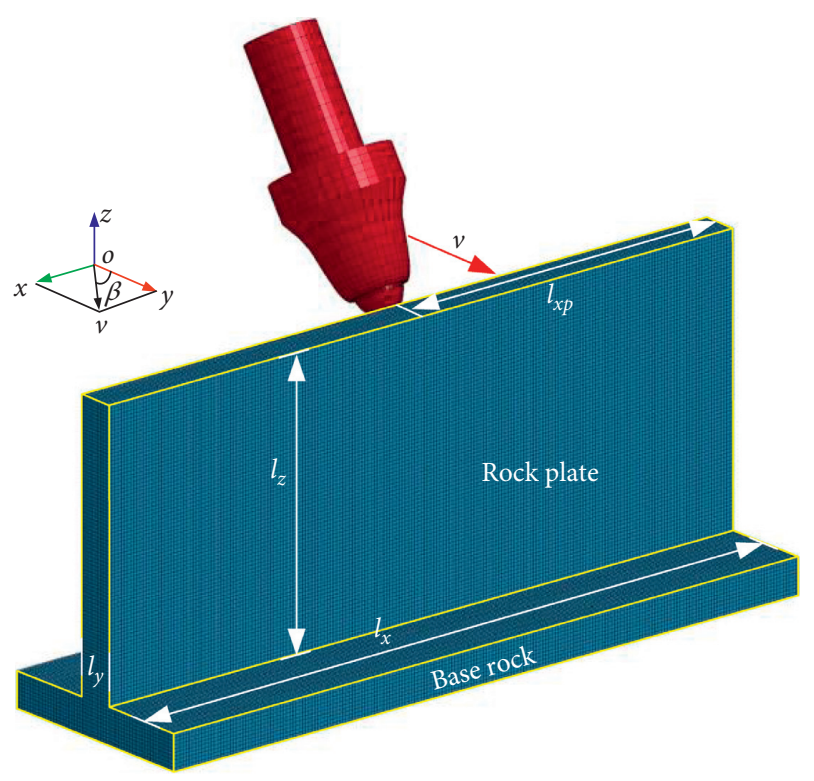

FIgURE 4: The finite element model of rock plate cutting.

$40 \mathrm{~mm}$ are shown in Figure 11. At the height of $20 \mathrm{~mm}$, the middle area of rock plate is broken, but the rock plate on both sides remains on the base rock, as is shown in Figure 11(a). At height of $40 \mathrm{~mm}$, rock plate fracture occurs at the middle part of the rock plate; in the meantime, the rock plate on both sides completely is fractured from the base rock, as can been seen in Figure 11(b). When the heights of rock plate increase to $80 \mathrm{~mm}$ and $160 \mathrm{~mm}$, the fracture of rock plate shows better integrity, as shown in Figures 11(c) and 11(d). Therefore, the conclusion can be drawn: the higher the rock plate is, the easier it is fractured.

The variations of PCF with rock plate height and the fitting relationship between them are shown in Figures 12 and 13. PCF decreases when the height of rock plate increases. From the fitting line, shown in Figure 13, and the fitting results, shown in Table 4, a linear negative correlation exists between PCF and height of rock plate. It is different from the exponential-positive relationship between width of rock plate and PCF. In the process of width increase from $200 \mathrm{~mm}$ to $500 \mathrm{~mm}$, the slope of the fitting line increases, which demonstrates that at the higher width, PCF changes more obviously with the height of rock plate. The minimum linear correlation coefficient between the height of rock plate and PCF is 0.95 and the $P$ value is less than 0.01 , indicating that the relationship is strong and the fitting results are credible.

\subsection{Influence of Thickness on Rock Plate Fracture.} Figure 14 shows the cutting results of rock plates with widths of $400 \mathrm{~mm}$, height of 160 , and thicknesses of $16 \mathrm{~mm}$ and $30 \mathrm{~mm}$, respectively. There exists some similarity in fracture morphology between Figures 11(d) and 14(a) with thickness of $16 \mathrm{~mm}$ and $20 \mathrm{~mm}$; that is, the cracks of rock plate are very regular. When the thickness of rock plate increases to $30 \mathrm{~mm}$, the fracture morphology changes significantly, and cracks are generated randomly, no longer along with the edge of the rock plate. So, if the rock plate is thicker, the shape of the broken rock plate is more random.

The relationships between PCF and thickness of rock plates with width of $400 \mathrm{~mm}$ and height of $160 \mathrm{~mm}$ are shown in Figure 15 and Table 4. It can be seen from Figure 15 that the PCF increases significantly with the increase of rock plate thickness. The fitting curve and equation show that exponential-positive relationship exists between PCF and thickness of rock plate. Simultaneously, the fitting results are satisfying, as is shown in Table 5.

3.4. Influence of Cutting Angle on Rock Plate Fracture. Figures $11(\mathrm{~d})$ and 16 show the cutting results of rock plate with cutting angles of $0^{\circ}, 10^{\circ}$, and $30^{\circ}$ at width of $400 \mathrm{~mm}$, height of $160 \mathrm{~mm}$, and thickness of $20 \mathrm{~mm}$. It can be seen from the comparison of the three figures that there is no difference in the fracture morphology of rock plate with different cutting angles.

Figure 17 shows the PCF variation with the cutting angle. With the increase of cutting angle, PCF increases first, with the cutting force reaching the maximum value at the cutting angle of $5^{\circ}$. Subsequently, PCF decreases with the increase of cutting angle, and when the cutting angle increases to $20^{\circ}$, 
TABLE 1: Detailed parameters of granite.

\begin{tabular}{lccccccccccc}
\hline$R_{0}$ & $G$ & $A$ & $B$ & $C$ & $N$ & $\mathrm{UCS}$ & $\mathrm{BTS}$ & $\mathrm{EPS} 0$ & $\mathrm{EF}_{\min }$ & $\mathrm{SF}_{\max }$ & PC \\
2683 & $2.2 e 10$ & 0.79 & 1.6 & 0.007 & 0.61 & $1.21 e 8$ & $1.21 e 7$ & $1 e-6$ & 0.01 & 12 & $5.7 e 7$ \\
\hline $\mathrm{UC}$ & $\mathrm{PL}$ & $\mathrm{UL}$ & $D_{1}$ & $D_{2}$ & $K_{1}$ & $K_{2}$ & $K_{3}$ & $\mathrm{FS}$ & $\mathrm{MNPRES}$ & $\mathrm{EPSSH}$ \\
0.0025 & $8 e 8$ & 0.08 & 0.04 & 1 & $8.5 e 10$ & $-1.7 e 11$ & $2 e 11$ & -1 & $-1.21 e 7$ & 1.5 & 7 \\
\hline
\end{tabular}

$R_{0}$ : mass density, $G$ : shear modulus, $A$ : normalized cohesive strength, $B$ : normalized pressure hardening, $C$ : strain rate coefficient, $N$ : pressure hardening exponent, EPS0: reference strain rate, EFMIN: amount of plastic strain before fracture, SFMAX: normalized maximum strength, PC: crushing pressure, UC: crushing volumetric strain, PL: locking pressure, UL: locking volumetric strain, $D_{1}$ : damage constant, $D_{2}$ : damage constant, $K_{1}$ : pressure constant, $K_{2}$ : pressure constant, $K_{3}$ : pressure constant, FS: failure type, MNPRES: minimum pressure at failure, and EPSSH: shear strain at failure [29].

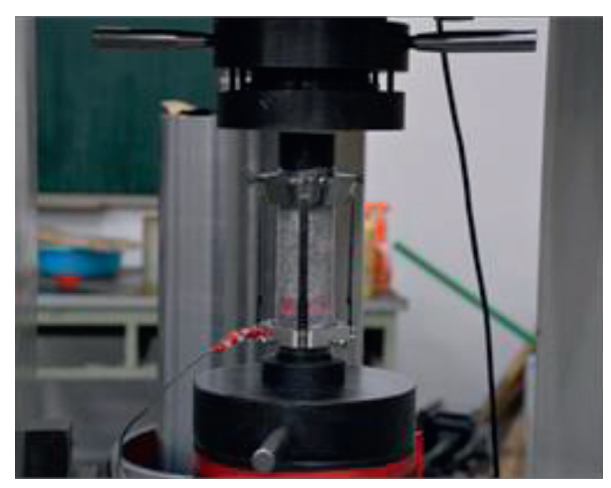

(a)

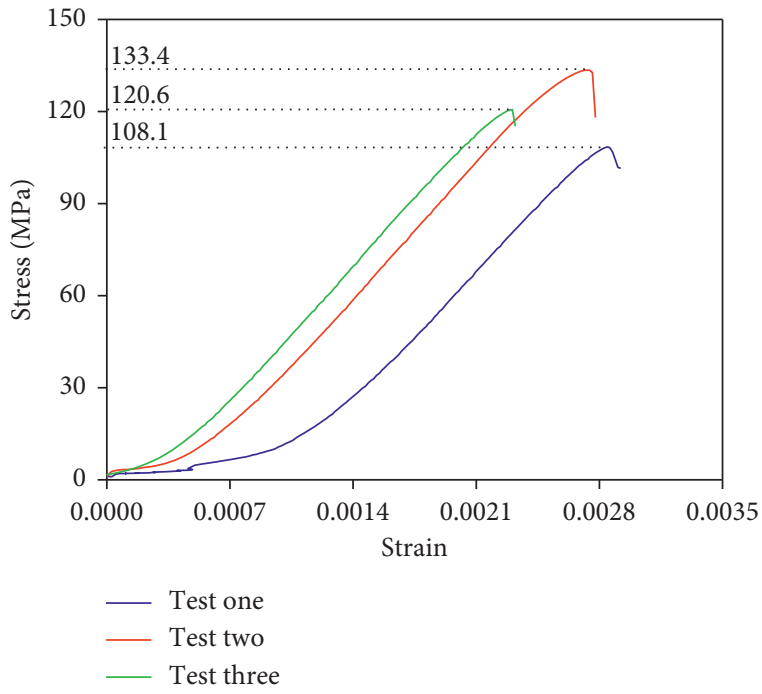

(b)

FIgURE 5: Rock compression test: (a) uniaxial compressive test and (b) the strain-stress curve.

TABLE 2: The mechanical properties of granite.

\begin{tabular}{lcccc}
\hline Rock & BTS $(\mathrm{MPa})$ & $\mathrm{UCS}(\mathrm{MPa})$ & $E(\mathrm{GPa})$ & \\
\hline Marble & 5.3 & 43.8 & 52.9 & 267.5 \\
Sandstone-1 & 7.9 & 86.4 & 54.5 & 2670 \\
Granite & 12.1 & 120.7 & 45.5 & 2683 \\
Sandstone-2 & 10.6 & 139.1 & 58.3 & 2732 \\
\hline
\end{tabular}

PCF keeps stable. Therefore, the PCF increases and decreases with the increase of cutting angle and then keeps stable. It can be concluded that the cutting angle had little effect on rock fracture morphology, but it had an obvious effect on PCF.

\subsection{Influence of Cutting Position on Rock Plate Fracture.} Figure 18 shows that the cutting results of rock plate with cutting position of $l_{x p}$ are equal to $1 / 8 l_{x}$ and $1 / 4 l_{x}$, respectively, at width of $500 \mathrm{~mm}$, height of $200 \mathrm{~mm}$, and thickness of $20 \mathrm{~mm}$. At the cutting position of $1 / 8 l_{x}$, rock plate fractures regionally, with only the area around conical pick separated from base rock. At the cutting position of $1 / 4 l_{x}$, the broken area of rock plate becomes larger, and, simultaneously, rock plate presents a tendency of overall fracture from the base rock. It can be seen that cutting positions have a significant impact on rock fracture.

The PCF variation with cutting position is shown in Figure 19, which shows that PCF increases with the increase of cutting position. At the widths of $500 \mathrm{~mm}$ and $400 \mathrm{~mm}$, the difference values between different cutting positions are $0.28 \mathrm{kN}$ and $0.33 \mathrm{kN}$, respectively. Therefore, from the perspective of numerical value, the PCF changes little.

3.6. Influence of Rock Property on Rock Plate Fracture. The cutting results with different rocks are shown in Figures 8 (d) and 20. It can be clearly seen that the cutting results of rock plates with different properties are obviously 


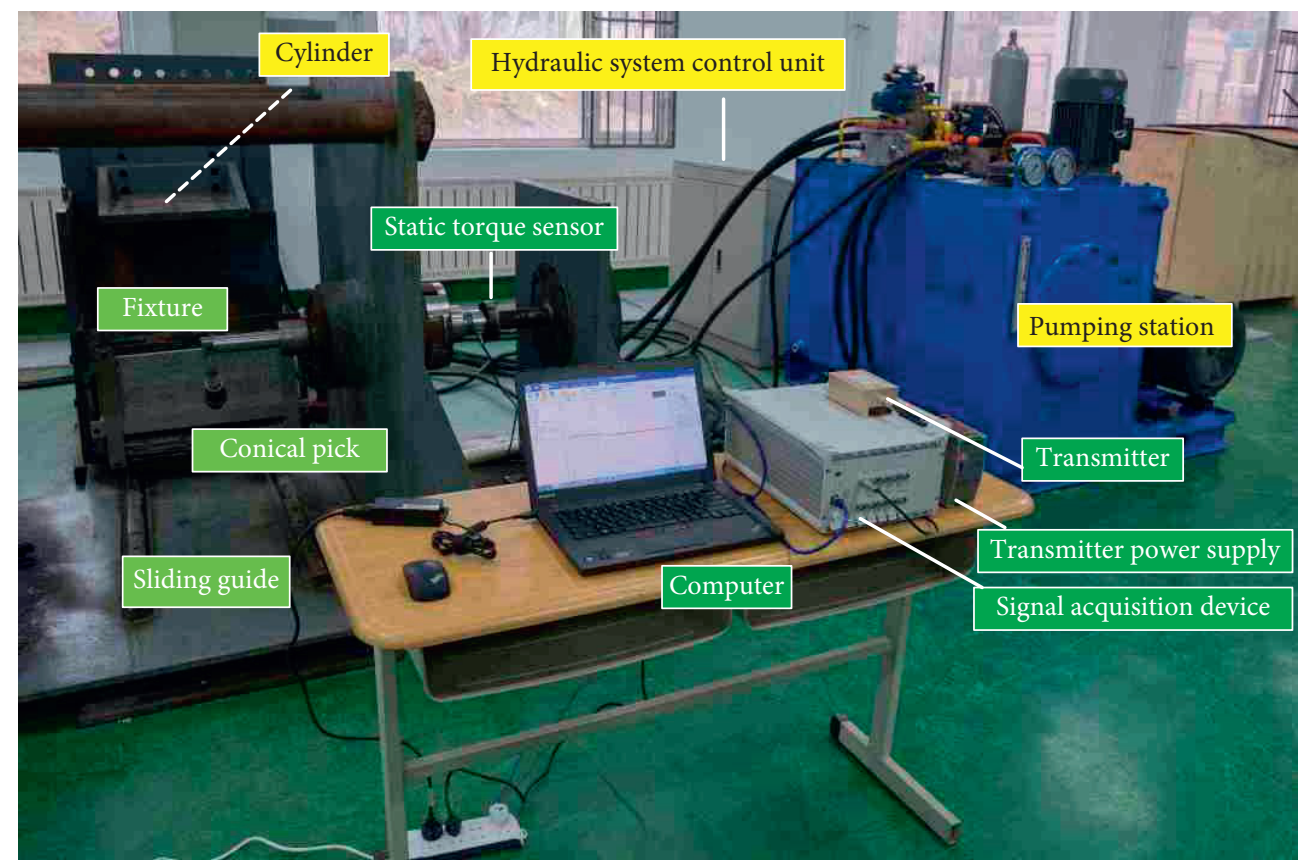

Hydraulic power system

Signal acquisition system

Rock cutting assembly

Figure 6: Rock plate cutting testbed [30].

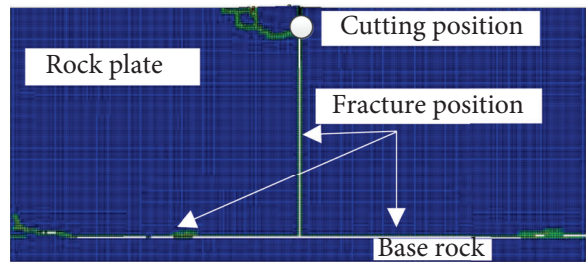

(a)

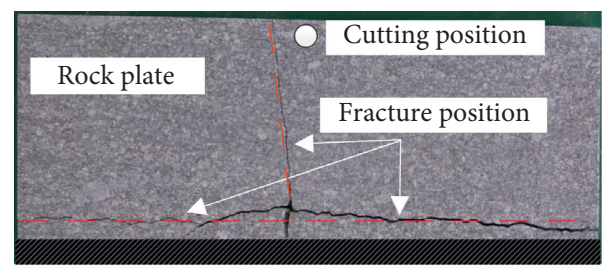

Fixed boundary

(b)

FIgURE 7: Comparison of experiment and numerical simulation results: (a) experimental result and (b) numerical simulation results.

different. The marble with the lowest compressive strength has a smaller fragment size and the largest number of fragments, as is shown in Figure 20(a). With increasing compressive strength, the number of fragmentations decreases, but the size of significant fragment increases. Therefore, the compressive strength of rock has obvious influence on the result of rock cutting.

Figure 21 shows the PCF increases obviously with the increase of UCS of rock plate. The peak cutting force of marble with compressive strength of $43.8 \mathrm{MPa}$ is $0.82 \mathrm{kN}$, while as to sandstone-2 with compressive strength of $139.1 \mathrm{MPa}$, the peak cutting force is 2.51 . According to the fitting curve, a strong exponential relationship exists between peak cutting force and rock compressive strength.
3.7. Cutting Process of the Rock Plate. When the conical pick acts upon the middle of rock plate, the cutting process of sandstone-1 with width of $400 \mathrm{~mm}$, height of $120 \mathrm{~mm}$, and thickness of $20 \mathrm{~mm}$ is shown in Figure 22, with the cutting results shown in Figure 20(b). With the contact between conical pick and rock plate, the cutting force increases. The elements of rock contacting with the pick are compressed and fail, thus forming a groove on the rock plate, as is shown in Figure 22(a). The groove can effectively increase the contact area between the pick and the rock plate, which causes the rock plate to bear higher cutting force. Figure 22(b) shows that a main crack is generated in the middle of rock plate when cutting force increases. Then, based on the main crack, cracks start to expand outward, as is shown in Figure 22(c). Finally, the cracks are connected with each other, further leading to rock fracture. 


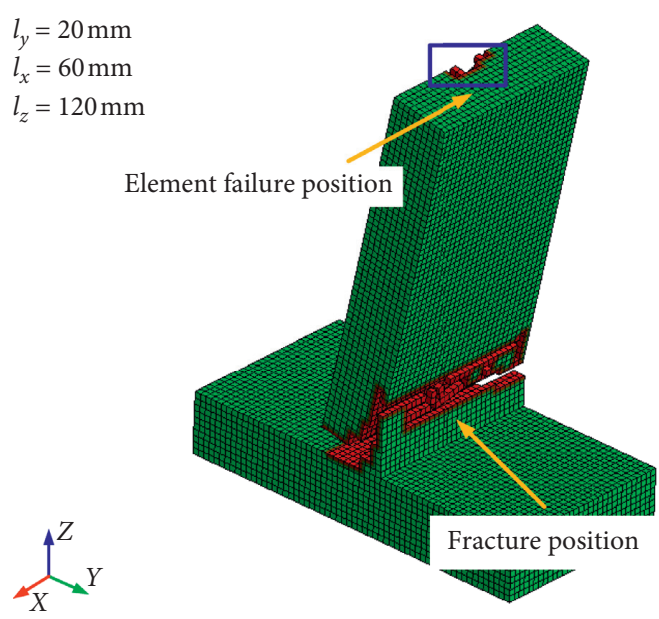

(a)

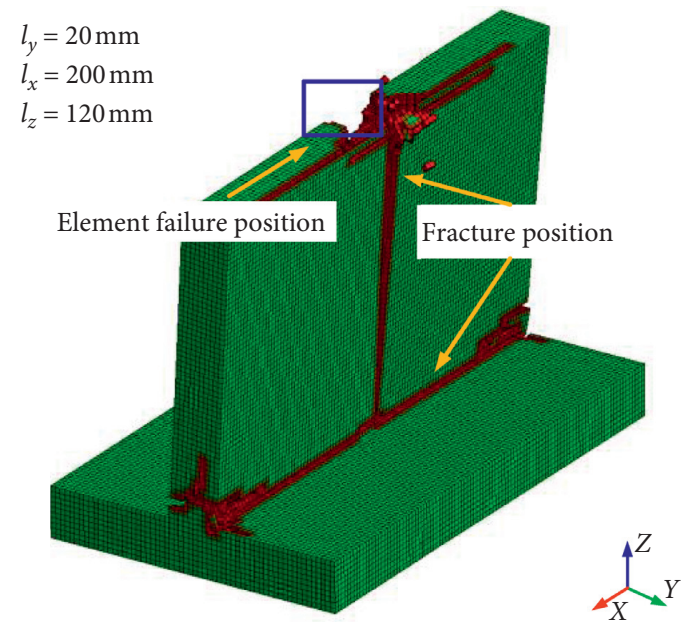

(c)

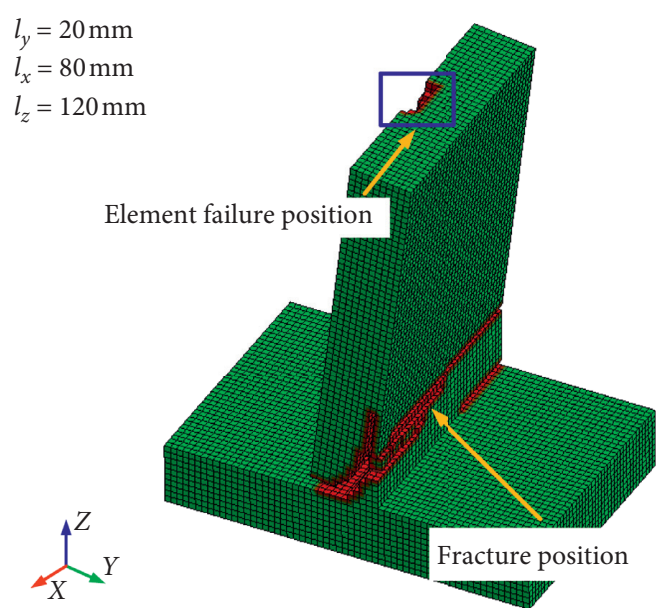

(b) $l_{y}=20 \mathrm{~mm}$
$l_{x}=400 \mathrm{~mm}$
$l_{z}=120 \mathrm{~mm}$

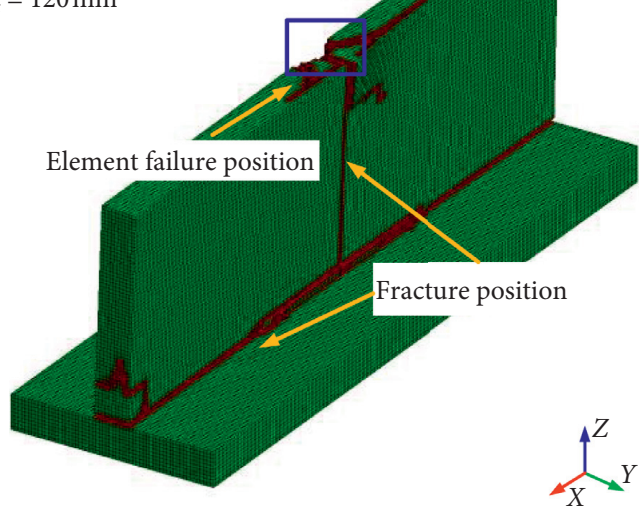

(d)

FIgURE 8: The rock plate cutting results with different widths: (a) $60 \mathrm{~mm}$, (b) $80 \mathrm{~mm}$, (c) $200 \mathrm{~mm}$, and (d) $400 \mathrm{~mm}$.

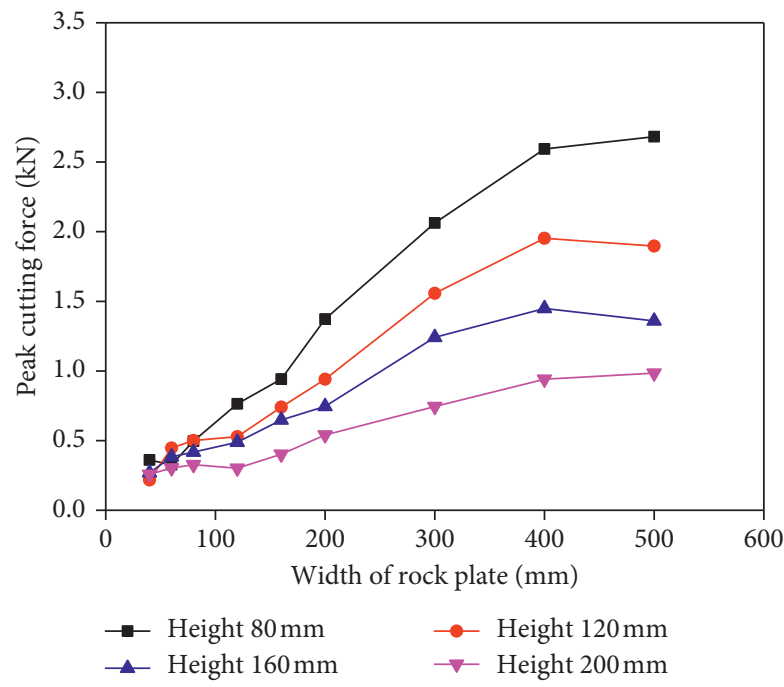

FIgURE 9: Variation in PCF with width. 


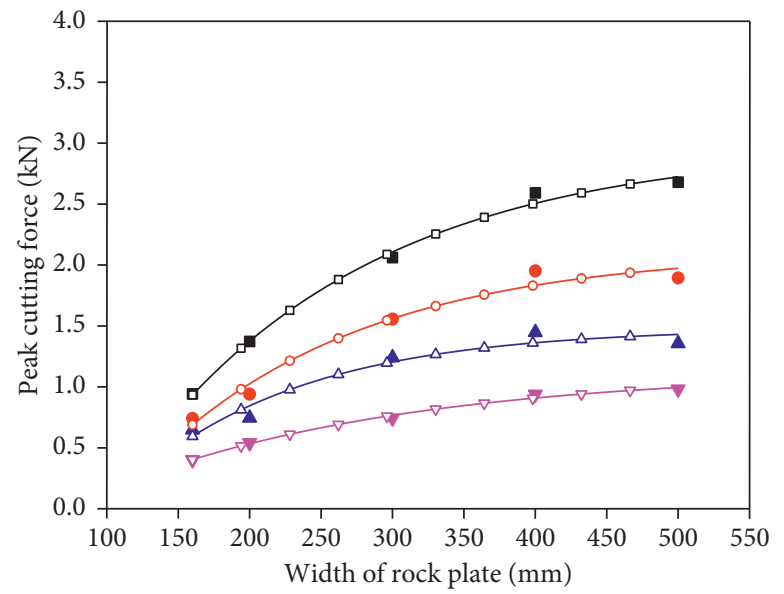

$\begin{array}{lcc}\text { Height } & \text { Simulation } & \text { Fitting } \\ 80 \mathrm{~mm} & \bullet & -\square- \\ 120 \mathrm{~mm} & \bullet & -\square \\ 160 \mathrm{~mm} & \Delta & -\checkmark \\ 200 \mathrm{~mm} & \nabla & -\square\end{array}$

Figure 10: The fitting curve between PCF and width of rock plate.

TABLE 3: Regression analysis results between width and PCF.

\begin{tabular}{lccccc}
\hline Height $(\mathrm{mm})$ & Fitting equation & $R^{2}$ & $F$ value & $P$ value & Correlation \\
\hline 80 & $y=2.98681-5.41959 \exp (-0.00607 x)$ & 0.98999 & 1207 & $8.3 e-4$ & Exponential-positive \\
120 & $y=2.12189-4.19385 \exp (-0.00671 x)$ & 0.95093 & 250 & $4.0 e-3$ & Exponential-positive \\
160 & $y=1.48716-3.34208 \exp (-0.00825 x)$ & 0.90044 & 160 & $6.2 e-3$ & Exponential-positive \\
200 & $y=1.1333-1.61165 \exp (-0.00495 x)$ & 0.98664 & 1132 & $8.8 e-4 \quad$ & Exponential-positive \\
\hline
\end{tabular}

$$
\begin{aligned}
& l_{y}=20 \mathrm{~mm} \\
& l_{z}=20 \mathrm{~mm} \\
& l_{x}=400 \mathrm{~mm}
\end{aligned}
$$

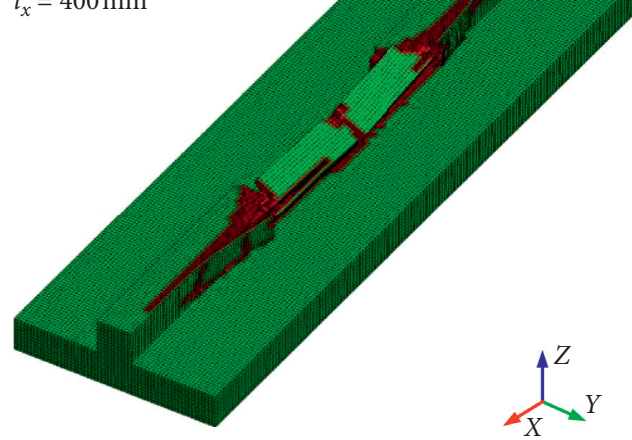

(a)

$$
\begin{aligned}
& l_{y}=20 \mathrm{~mm} \\
& l_{z}=80 \mathrm{~mm} \\
& l_{x}=400 \mathrm{~mm}
\end{aligned}
$$

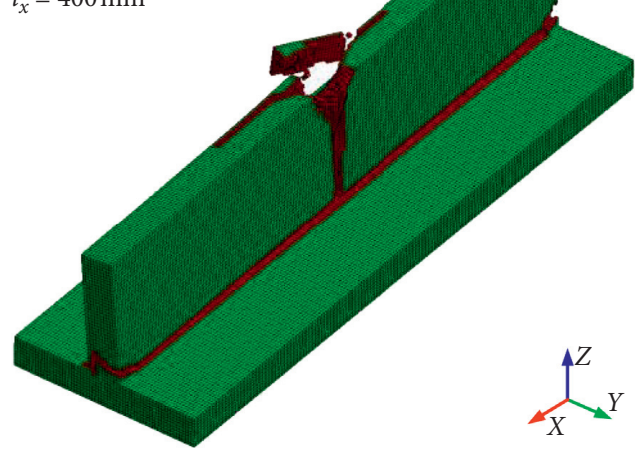

(c)

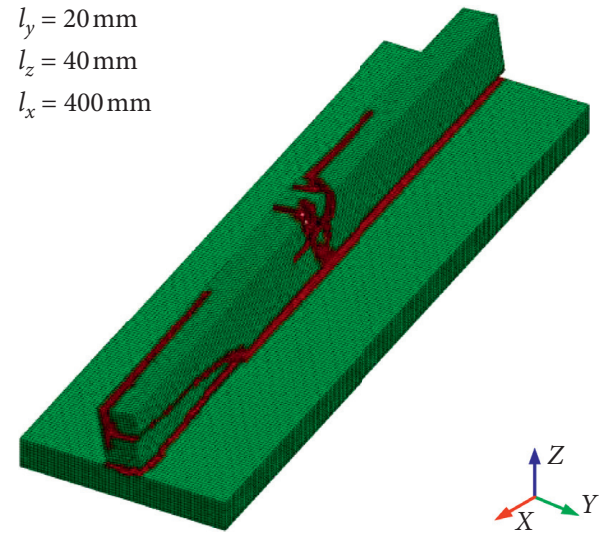

(b)

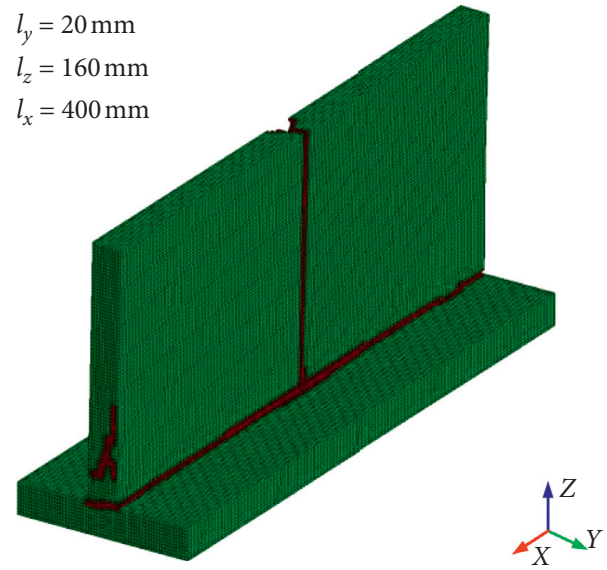

(d)

Figure 11: Results of rock plate cutting with different heights: (a) $20 \mathrm{~mm}$, (b) $40 \mathrm{~mm}$, (c) $80 \mathrm{~mm}$, and (d) $160 \mathrm{~mm}$. 


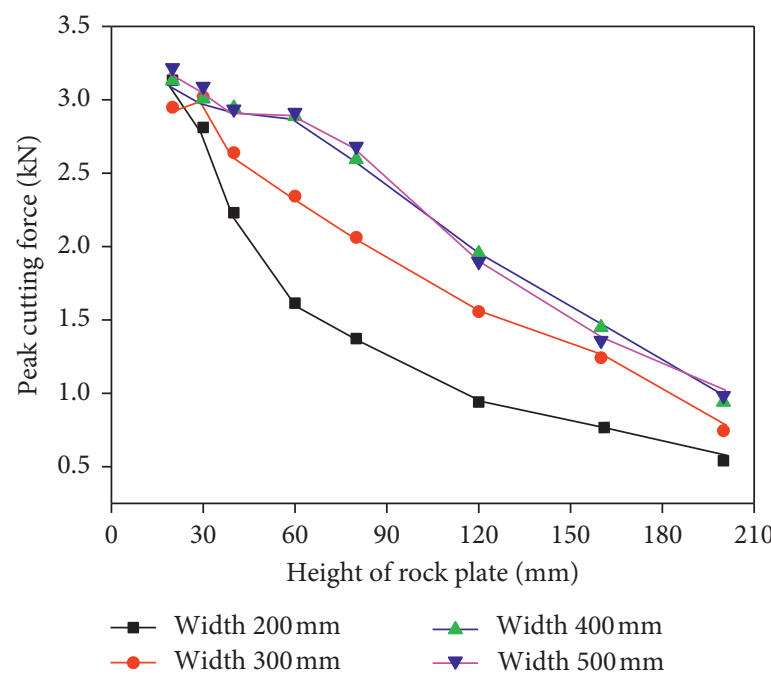

Figure 12: Variations in PCF with width.

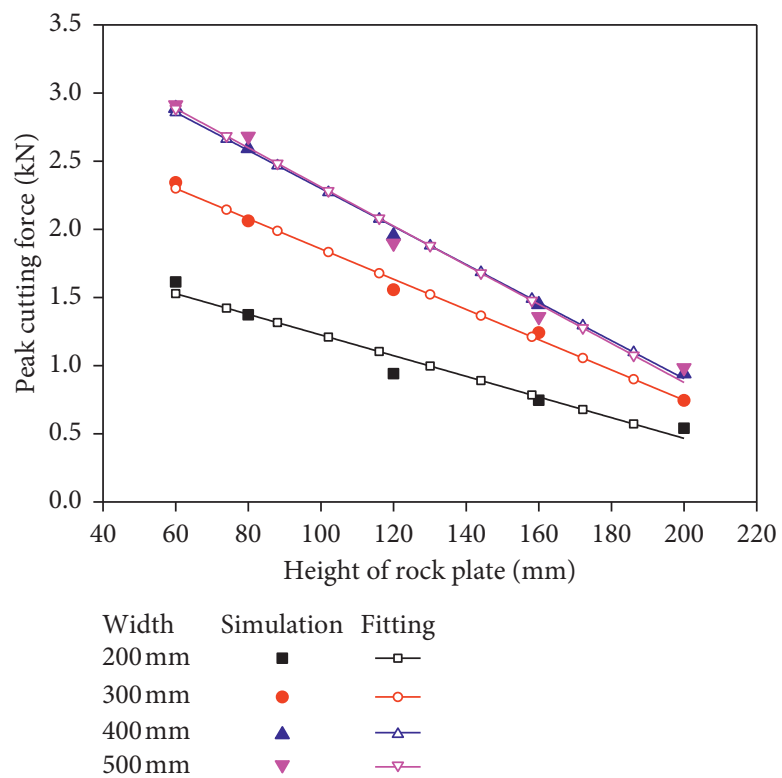

Figure 13: Fitting curves between PCF and width of rock plate.

TABLE 4: Regression analysis results between height and PCF.

\begin{tabular}{lccccr}
\hline Width $(\mathrm{mm})$ & Fitting equation & $R^{2}$ & $F$ value & $P$ value & Correlation \\
\hline 200 & $y=1.9834-0.00758 x$ & 0.94744 & 73 & $3.3 e-3$ & Linear-negative \\
300 & $y=2.96567-0.0111 x$ & 0.99119 & 451 & $2.3 e-4$ & Linear-negative \\
400 & $y=3.69552-0.01396 x$ & 0.99623 & 1058 & $6.4 e-5$ & Linear-negative \\
500 & $y=3.74685-0.01435 x$ & 0.97869 & 184 & $8.6 e-4$ & Linear-negative \\
\hline
\end{tabular}

\section{Conclusion}

In order to study the fracture mechanism of rock plate with three sides fixed and one side free, the interaction model between the conical pick and rock plate is built. The PCF and rock fracture characteristic with different cutting parameters and rock parameters are researched.
(1) In order to generate crack and separate fragment in the process of rock plate cutting, ERODING_SURFACE_TO_SURFACE and EROSION are added in the numerical model. By comparing with the experimental results, it is shown that the numerical model proposed in the paper is feasible and accurate. 


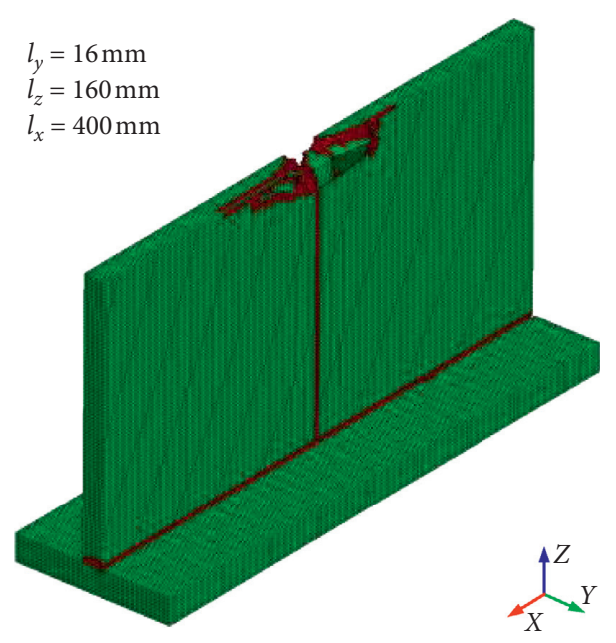

(a)

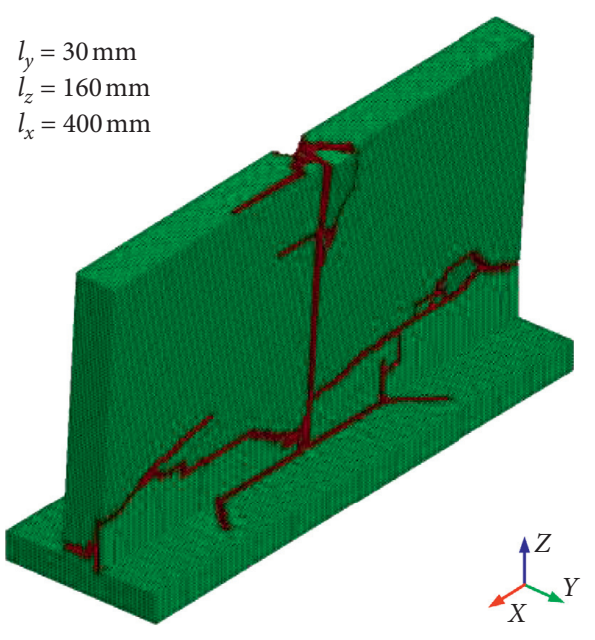

(b)

Figure 14: Cutting results of rock plate with different thicknesses: (a) $16 \mathrm{~mm}$ and (b) $30 \mathrm{~mm}$.

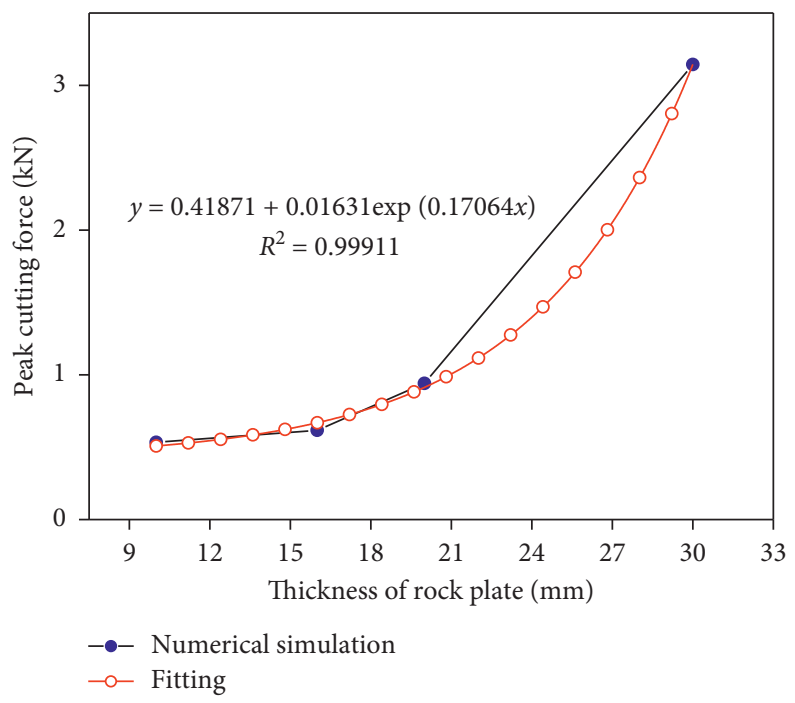

FIgURE 15: The relationship between PCF and thickness of rock plate.

TABLE 5: Regression analysis results between thickness and PCF.

\begin{tabular}{lcccc}
\hline Fitting equation & $R^{2}$ & $F$ value & $P$ value & Correlation \\
\hline$y=1.1333-1.61165 \exp (-0.00495 x)$ & 0.98664 & 1132 & $8.8 e-4$ & Exponential-positive \\
\hline
\end{tabular}

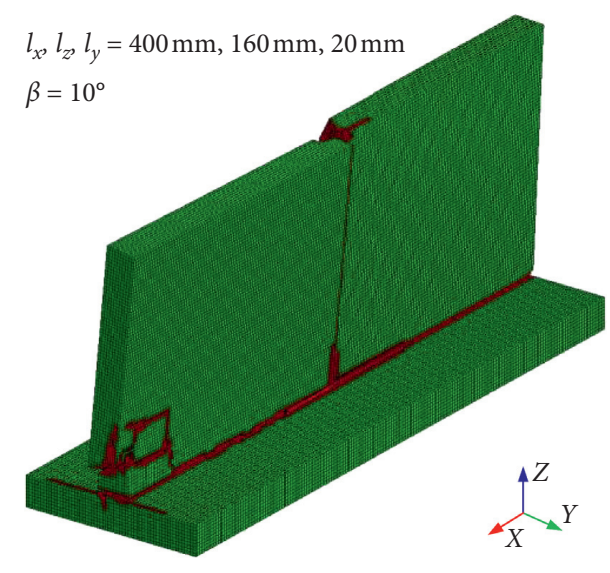

(a)

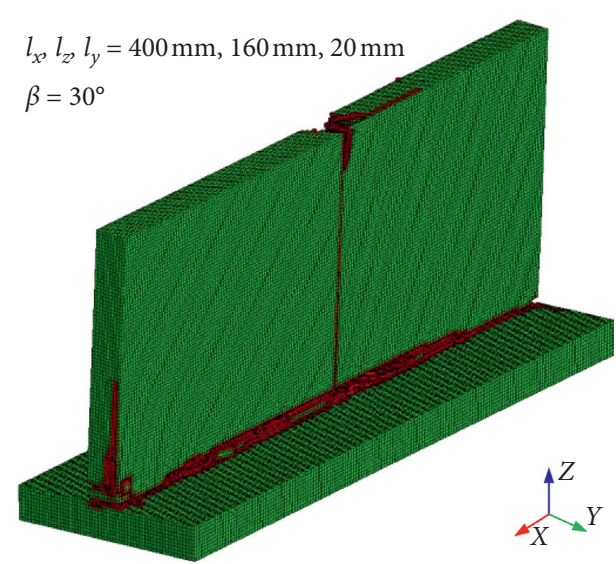

(b)

FIgURE 16: Numerical results of rock plates with different cutting angles: (a) $\beta=10^{\circ}$ and (b) $\beta=30^{\circ}$. 


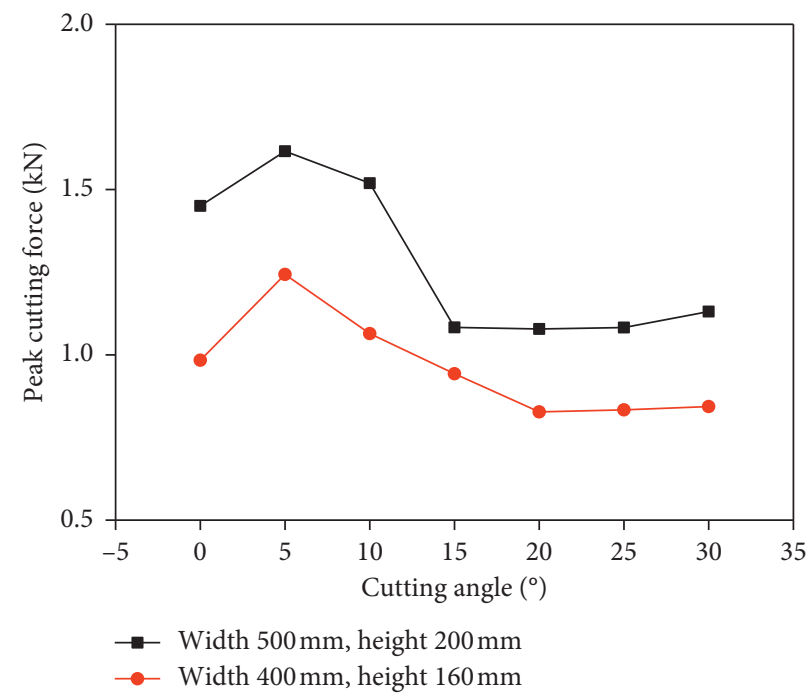

FIGURE 17: Variation in peak cutting force with cutting angle.

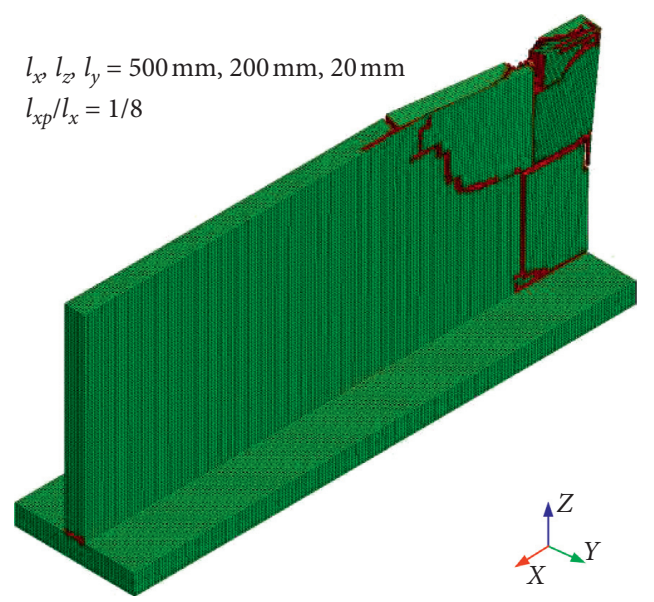

(a)

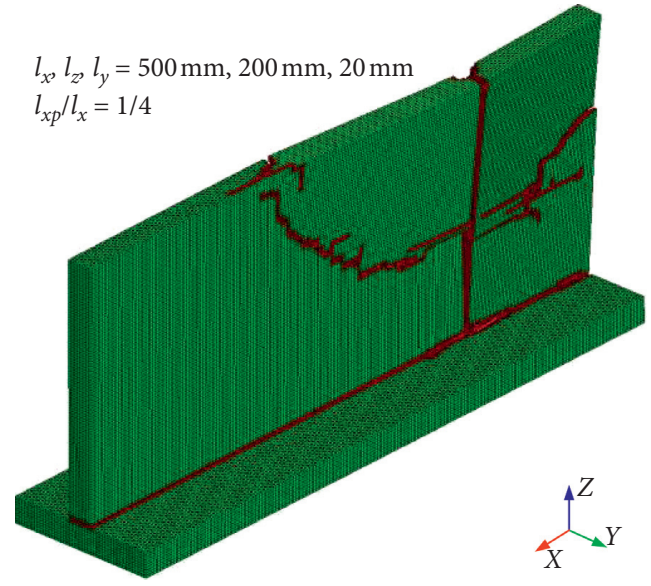

(b)

FIGURE 18: Cutting results of rock plate at different cutting positions: (a) $l_{x p} / l_{x}=1 / 8$ and (b) $l_{x p} / l_{x}=1 / 4$.

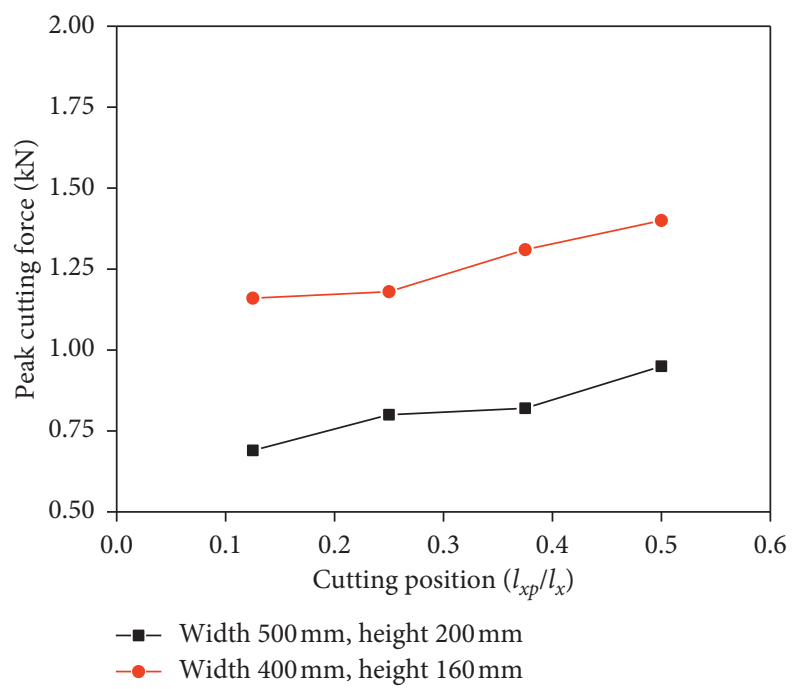

FIGURE 19: Variation in peak cutting force with cutting position. 


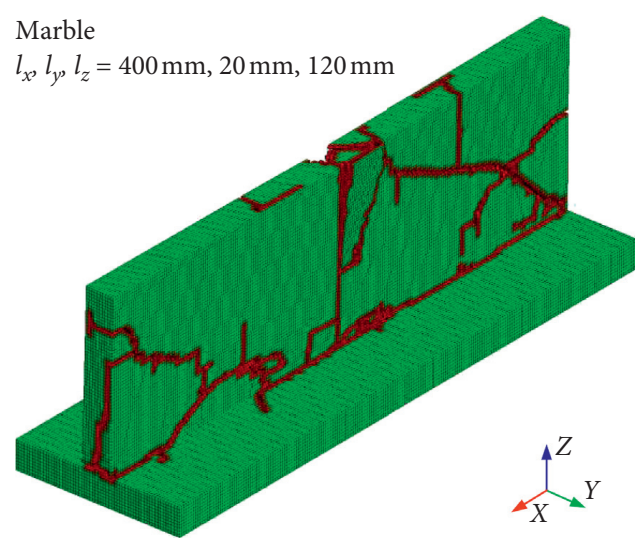

(a)

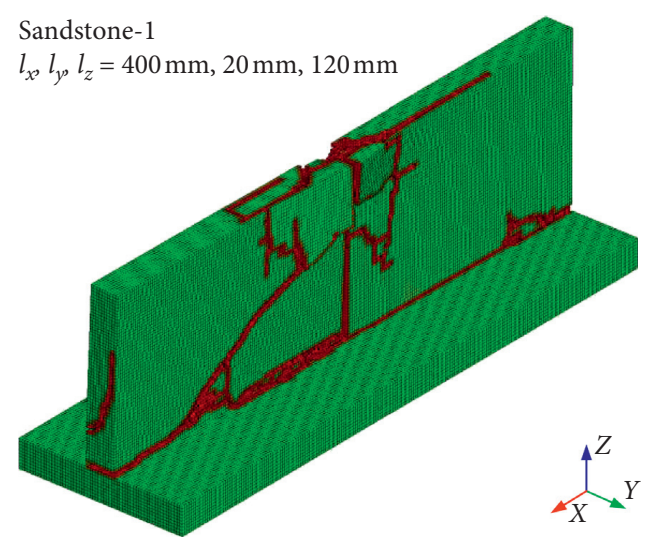

(b)

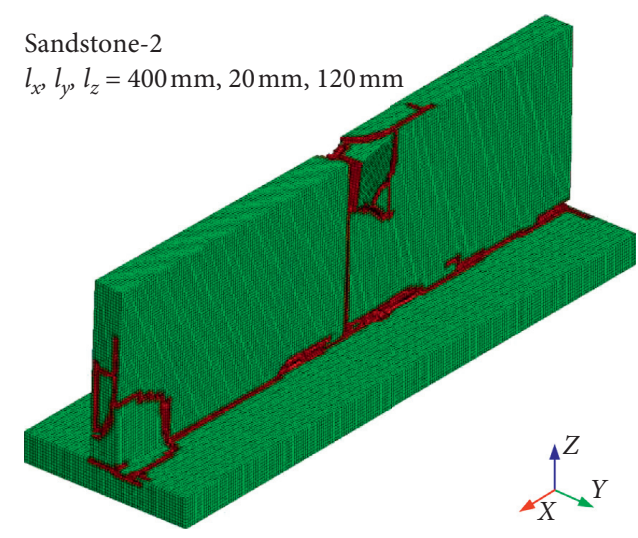

(c)

FIgURE 20: Cutting results of rock plates with rocks: (a) marble, (b) sandstone-1, and (c) sandstone-2.

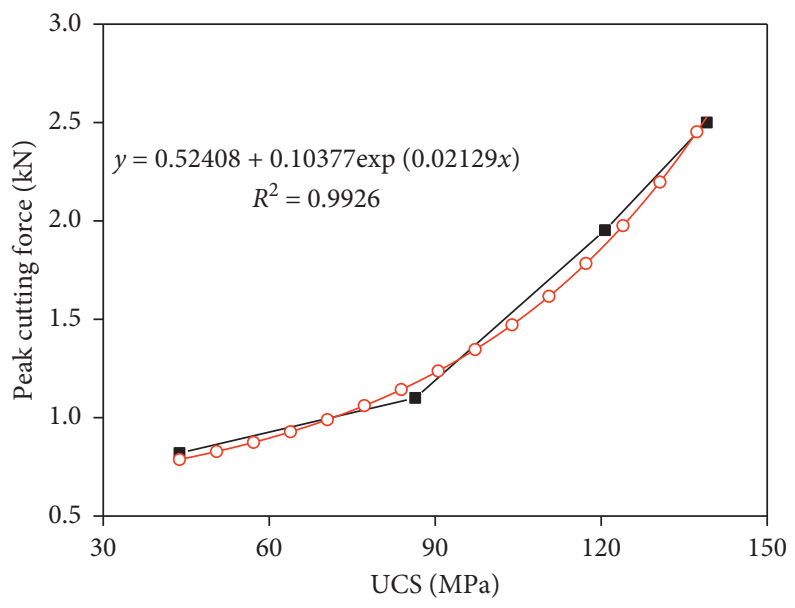

FIgURE 21: Relationship between UCS and peak cutting force.

(2) The cutting results obtained from different widths, heights, and thicknesses of rock plates show that PCF increases when the thickness and width of rock plate increase, and that it decreases when the height of rock plate increases. The positive exponential relationship exists between PCF and thickness and width of rock plate, and the linear relationship exists between PCF and height of rock plate. Furthermore, thickness has the most significant influence on PCF.

(3) PCF also varies with different cutting angles and cutting positions. With the increasing cutting angle, PCF increases and then decreases, and, finally, it tends to be stable. With the increasing cutting position, PCF increases. However, the change of cutting 


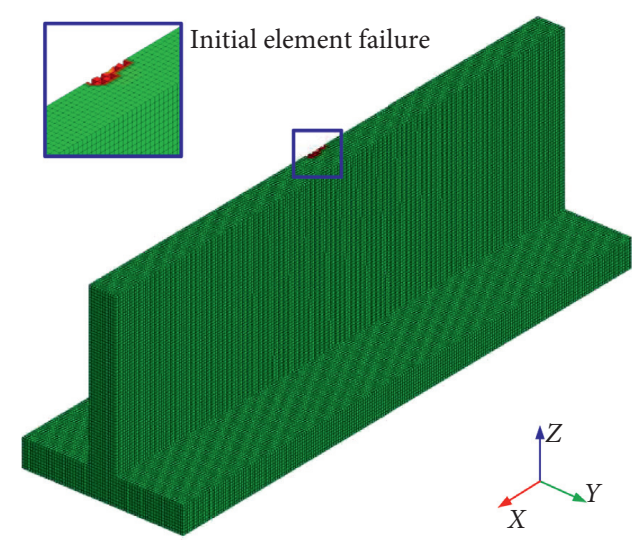

(a)

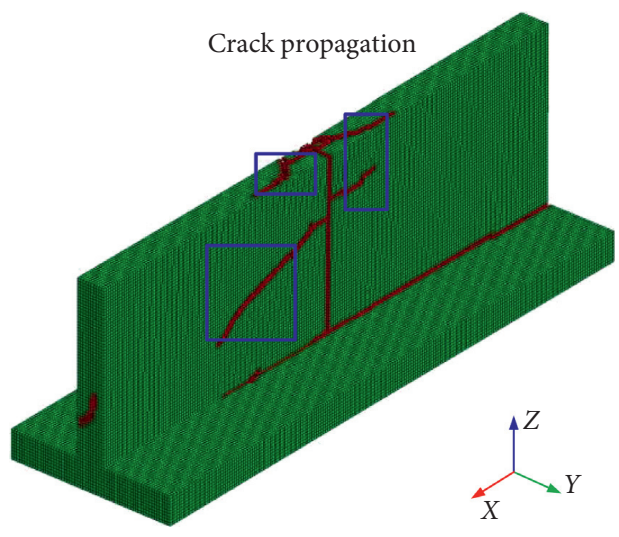

(c)

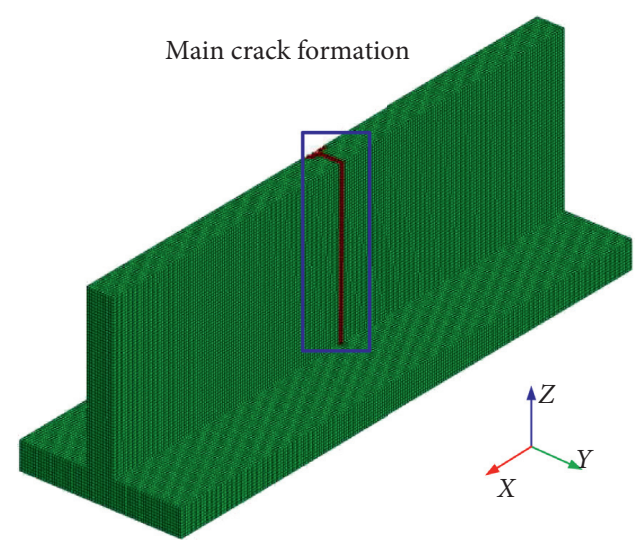

(b)

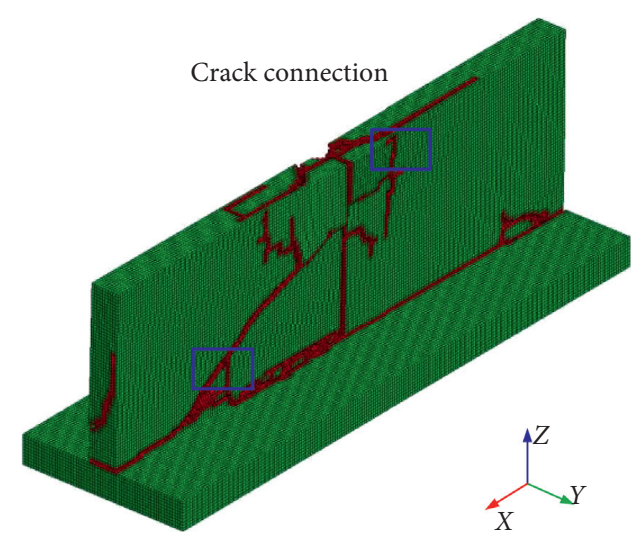

(d)

Figure 22: Cutting process of sandstone- 1 with width of 400, height of $120 \mathrm{~mm}$, and thickness of $20 \mathrm{~mm}$ : (a) initial element failure, (b) main crack formation, (c) crack propagation, and (d) crack connection.

force with cutting angle and cutting position is relatively small.

(4) From the perspective of rock fragmentation, although the width of the rock plate has an effect on the rock fracture results, rock plates are completely broken. Otherwise, lower thickness and higher height benefit rock fracture integrally. Cutting angle has little influence on rock fracture results. The closer the conical pick is to the middle of the rock plate, the more favorable it is for rock plate fracture.

\section{Data Availability}

The data used to support the findings of this study are included within the article.

\section{Conflicts of Interest}

The authors declare that there are no conflicts of interest regarding the publication of this paper.

\section{Acknowledgments}

This work was supported by the Natural Science Foundation of Shandong Province (Grant nos. ZR2019BEE069 and ZR2019MEE067), Open Fund of Shandong Province Key
Laboratory of Mine Mechanical Engineering (Grant no. 2019KLMM203), and Project of Shandong Province Higher Educational Young Innovative Talent Introduction and Cultivation Team (performance enhancement of deep coal mining equipment).

\section{References}

[1] N. Bilgin, H. Copur, and C. Balci, Mechanical Excavation in Mining and Civil Industries, CRC Press, Taylor \& Francis Group, Boca Raton, FL, USA, 2014.

[2] I. Evans, "A theory of the cutting force for point-attack picks," International Journal of Mining Engineering, vol. 2, no. 1, pp. 63-71, 1984.

[3] F. F. Roxborough and Z. C. Liu, "Teoretical considerations on pick shape in rock and coal cutting," in Proceedings of the Sixth Underground Operator's Conference, pp. 189-193, Kalgoorlie, Australia, November 1995.

[4] R. M. Goktan, “A suggested improvement on Evans' cutting theory for conical bits," in Proceedings of the Fourth International Symposium on Mine Mechanization and Automation, pp. 57-61, Queensland, Australia, 1997.

[5] R. M. Goktan and N. Gunes, "A semi-empirical approach to cutting force prediction for point-attack picks," The Journal of The South African Institute of Mining and Metallurgy, vol. 105, no. 4, pp. 257-263, 2005. 
[6] B. Tiryaki, J. N. Boland, and X. S. Li, "Empirical models to predict mean cutting forces on point-attack pick cutters," International Journal of Rock Mechanics and Mining Sciences, vol. 47 , no. 5, pp. 858-864, 2010.

[7] C. S. Liu and L. H. Jin, "The cut mechanical model of pickshaped cutter under conditions of dissymmetrical slotting," Journal of China Coal Society, vol. 34, no. 7, pp. 983-987, 2009.

[8] N. Bilgin, M. A. Demircin, H. Copur, C. Balci, H. Tuncdemir, and N. Akcin, "Dominant rock properties affecting the performance of conical picks and the comparison of some experimental and theoretical results," International Journal of Rock Mechanics and Mining Sciences, vol. 43, no. 1, pp. 139-156, 2006.

[9] H. Kang, J.-W. Cho, J.-Y. Park et al., “A new linear cutting machine for assessing the rock-cutting performance of a pick cutter," International Journal of Rock Mechanics and Mining Sciences, vol. 88, pp. 129-136, 2016.

[10] S. Dewangan and S. Chattopadhyaya, "Performance analysis of two different conical picks used in linear cutting operation of coal," Arabian Journal for Science and Engineering, vol. 41, no. 1, pp. 249-265, 2015.

[11] S. Yasar and A. O. Yilmaz, "Vertical rock cutting rig (VRCR) suggested for performance prediction of roadheaders," International Journal of Mining, Reclamation and Environment, vol. 33, no. 3, pp. 149-168, 2017.

[12] J. Huang, Y. Zhang, L. Zhu, and T. Wang, "Numerical simulation of rock cutting in deep mining conditions," International Journal of Rock Mechanics and Mining Sciences, vol. 84, pp. 80-86, 2016.

[13] X. Wang, Q.-F. Wang, Y.-P. Liang, O. Su, and L. Yang, "Dominant cutting parameters affecting the specific energy of selected sandstones when using conical picks and the development of empirical prediction models," Rock Mechanics and Rock Engineering, vol. 51, no. 10, pp. 3111-3128, 2018.

[14] O. Su, "Numerical modeling of cuttability and shear behavior of chisel picks," Rock Mechanics and Rock Engineering, vol. 52, no. 6, pp. 1803-1817, 2018.

[15] X. Wang and O. Su, "Specific energy analysis of rock cutting based on fracture mechanics: a case study using a conical pick on sandstone," Engineering Fracture Mechanics, vol. 213, pp. 197-205, 2019.

[16] S. Yasar, "Determination of optimum rock cutting data through single pick cutting tests," Géotechnique Letters, vol. 9, no. 1, pp. 8-14, 2019.

[17] S. Yasar, "A general semi-theoretical model for conical picks," Rock Mechanics and Rock Engineering, vol. 53, no. 6, pp. 2557-2579, 2020.

[18] Z. Lu, L. Wan, Q. Zeng, X. Zhang, and K. Gao, "Numerical simulation of rock plate cutting with three sides fixed and one side free," Advances in Materials Science and Engineering, vol. 2018, Article ID 5464295, 21 pages, 2018.

[19] D. Yang, J. Li, L. Wang, K. Gao, Y. Tang, and Y. Wang, "Experimental and theoretical design for decreasing wear in conical picks in rotation-drilling cutting process," The International Journal of Advanced Manufacturing Technology, vol. 77, no. 9-12, pp. 1571-1579, 2014.

[20] S. Dewangan, S. Chattopadhyaya, and S. Hloch, "Wear assessment of conical pick used in coal cutting operation," Rock Mechanics and Rock Engineering, vol. 48, no. 5, pp. 2129-2139, 2014.

[21] H. Michael, "Cutting strong rock with a drag bit assisted by high-pressure water jets," Journal of The South African Institute of Mining and Metallurgy, vol. 77, no. 4, pp. 79-90, 1976.
[22] T. Stoxreiter, A. Martin, D. Teza, and R. Galler, "Hard rock cutting with high pressure jets in various ambient pressure regimes," International Journal of Rock Mechanics and Mining Sciences, vol. 108, pp. 179-188, 2018.

[23] J. Poláček and E. Janurová, "Impact of pressure of surrounding medium on plain water jet cutting of rocks," The International Journal of Advanced Manufacturing Technology, vol. 90, no. 5-8, pp. 2185-2191, 2016.

[24] S. Wang, X. Li, J. Yao et al., "Experimental investigation of rock breakage by a conical pick and its application to nonexplosive mechanized mining in deep hard rock," International Journal of Rock Mechanics and Mining Sciences, vol. 122, Article ID 104063, 2019.

[25] X. Liu, P. Tang, Q. Geng, X. Li, and M. Tian, "Numerical research on wear mechanisms of conical cutters based on rock stress state," Engineering Failure Analysis, vol. 97, pp. 274287, 2019.

[26] X. Liu, P. Tang, X. Li, and M. Tian, "Self-rotatory performance of conical cutter interacted with rock material," Engineering Failure Analysis, vol. 80, pp. 197-209, 2017.

[27] H. S. Li, S. Y. Liu, and P. P. Xu, "Numerical simulation on interaction stress analysis of rock with conical picks," Tunnelling and Underground Space Technology, vol. 85, pp. 231242, 2019.

[28] E. Kim, K. Hirro, D. Oliveira, and A. Kim, "Effects of the skew angle of conical bits on bit temperature, bit wear, and rock cutting performance," International Journal of Rock Mechanics and Mining Sciences, vol. 100, pp. 263-268, 2017.

[29] T. J. Holmquist, G. R. Johnson, and W. H. Cook, "A computational consititutive model for concrete subjected to large strains, high strain rates, and high pressures," in Proceedings of the Fourteenth International Symposium on Ballistics, pp. 110, Quebec City, Canada, September 1993.

[30] Z. Lu, Q. Zeng, Z. Wang, X. Li, and K. Gao, "Experimental and numerical studies on rock cutting with saw blade and conical pick combined cutting method," Mathematical Problems in Engineering, vol. 2019, Article ID 5046873, 14 pages, 2019. 